\title{
Sustainable Climate Change Adaptations in Developing Countries: A Case Study of the Turkish Cypriot Community's Adoption of Pomegranate Farming
}

\author{
Clare M. Finnegan and Omer Gokcekus
}

\begin{abstract}
Climate change is a growing issue for developing countries, as they typically lack the technical and financial inputs to implement the necessary agricultural adaptations. These countries also suffer from the classic collective action problem; although they are able to identify the issue and a potential solution, their individual resources are not substantial enough to enact change. This article discusses north Cyprus' 2006 adoption of pomegranate production and its relationship to climate-related agricultural concerns. We argue that the Turkish Cypriot community would not have been able to start an effective pomegranate agribusiness without third-party financial and technical assistance. As a post-conflict developing community, they lacked the resources necessary to collectivize on their own and initiate crop switching. Thus, Turkish Cypriot farmers needed external resources in order to launch a sustainable development project. The programme was a successful example of sustainable peacebuilding as it required local ownership.
\end{abstract}

\section{Introduction ${ }^{1}$}

Climate change used to be an abstract, futuristic problem. Although there was some awareness of the need to adapt one's lifestyle to be more "environmentally friendly", the problem lacked urgency and was perceived as an issue that the coming generation would tackle. Now it seems to be an inescapable reality. Developed countries with abundant resources, like the USA, have been able to implement certain adaptations to mitigate some of the adverse effects of climate change. How have other less affluent countries adapted?

\footnotetext{
${ }^{1}$ Any information not directly cited is attributable to interviews and personal correspondence with Berna Berberoğlu, the deputy project manager of the Economic Development and Growth for Enterprises (EDGE) programme, and İbrahim Kahramanoğlu, the managing director of Alnar Narc1lık Ltd.

C.M. Finnegan • O. Gokcekus $(\bowtie)$

School of Diplomacy and International Relations, Seton Hall University, South Orange, NJ 07039, USA

e-mail: finneganclare@msn.com; omer.gokcekus@shu.edu
} 
As what Gokcekus and Bengyak (2014) discuss in regard to corruption, climate change has the most severe ill effects on those members of society (or the world) that are least capable of preparing themselves for its impact. Often still largely agriculturally based, the economies of many developing countries are especially vulnerable to environmental changes. Limited financial resources create a collective action problem; while the individual members of a developing society may know that the adaptation or modification of existing processes can help combat climate-related issues, they lack the resources - technical and financial-to adopt these changes. The problem of adaptation is particularly acute in post-conflict regions that have been isolated from beneficial economic relationships, such as north Cyprus.

North Cyprus has been a de facto separate country since Cyprus was partitioned by the "Green Line"-a UN buffer zone-in 1974 due to conflict between Cypriots of Greek ancestry and those of Turkish (BBC 2011). Under the internationally recognized Republic of Cyprus, Greek Cypriots were able to interface with the EU and the greater international community. North Cyprus was isolated, and its economic development has lagged behind that of the Republic of Cyprus. On average, Greek Cypriots have a $61 \%$ higher per capita income than Turkish Cypriots (Gokcekus 2008, p. 15). This paper will explore how intervention by a third party helped the Turkish Cypriot community (TCC) adapt its agricultural industry to the constraints of climate change and simultaneously overcome its collective action problem. Specifically, this paper explores USAID's 2006 agribusiness programme that assisted the TCC with starting commercial production of the nutritional superfruit pomegranate.

\section{Crop Switching and Sustainable Peacebuilding}

Why does climate change matter? Kurukulasuriya and Mendelsohn (2008) try to predict the impact of climate change on farms' output and revenue in 11 African countries. Under one climate change scenario-the Canadian Climate Centre (CCC) model in which the studied regions become hotter and drier-predicted revenues for the year 2100 would decline by nearly $70 \%$ if farmers did not participate in crop switching (p. 122). In an alternative climate change scenariothe Parallel Climate Model (PCM) in which the climate of the studied regions becomes mild and wet-revenues were actually expected to significantly (82\%) increase. Which of these two models most closely predicts future conditions is currently unknown. In order to avoid a potential $70 \%$ loss of revenue, the authors suggest crop switching; under the CCC's conditions, crop switching could reduce losses to only $6 \%$.

Seo and Mendelsohn (2008) also explored crop choice and its relationship to climate change, focusing on South American farms. As in Africa, crop choice in South America generally had an identifiable, significant relationship with temperature and precipitation. The one exception to this was maize, a crop with many 
varieties that are adaptable to most South American climates. Seo and Mendelsohn (2008) did not predict the economic impact of not crop switching, but instead assumed that farmers - making a rational economic decision-would switch.

Huda et al. (2005) suggest measures that farmers, community workers, and policy agencies can take in response to changing environmental conditions. Huda et al. were primarily concerned with the possible mismatch between crop phenology and water availability caused by climate change. Without an understanding of phenology, crop adaptation proves difficult as crops with certain phenologies only thrive in specific ecosystems. Huda et al. (2005) therefore recommend several strategies, such as changing the time of planting and adopting alternative crops, that could help mitigate mismatch between crop phenology and water resources (p. 142).

Farmers can only combat climate change by employing crop switching if "there are no barriers to the adoption of appropriate crops" (Kurukulasuriya and Mendelsohn 2008, p. 123). Seo and Mendelsohn (2008) echoed this warning, specifically mentioning that farmers may not be able to crop switch "if the adjustment requires a heavy capital investment" (p. 115). Lobell et al. (2008) argue that while "switching to an existing crop variety may moderate negative impacts, the biggest benefits will likely result from more costly measures..." (p. 607). In addition to potential financial constraints, the measures advocated by Huda et al. (2005) generally require significant technical or scientific acumen, knowledge that is often in short supply in developing nations.

These financial and technical constraints only exacerbate the collective action problem, which is particularly acute when resources are scarce. In a society with limited inputs, the participation of many actors (a group effort) is often necessary in order to secure opportunities or goods that enhance the collective benefit. As Olson (1965) details, large groups are particularly prone towards free-ridership, since members of the group believe their non-participation will be overlooked. This tendency is especially detrimental to projects in developing countries; the constrained resources of individual members in these countries often require that collective goods be provided through larger-sized groups with high levels of participation.

How can developing countries, particularly post-conflict societies like Cyprus, solve these challenges? Gokcekus et al. (2014) suggest that the solution lies with intervention by an outside actor. In their study of Turkish Cypriot beekeepers, Gokcekus et al. found that the beekeepers needed EU financial and technical assistance to overcome their collective action problem, meet the EU's health standards for commercial honey, and initiate trade across the Green Line. The EU provided the initial impetus for change; once the Turkish Cypriots beekeepers understood the standard requirements for trade and had the financial resources to meet these standards, they were able to collectivize and increase their level of economic development. In other words, although the process of updating their beekeeping practices to meet EU standards was instigated by the EU, Turkish Cypriot beekeepers accepted local ownership of the remainder of the development process. 
As Donais (2009) notes, local ownership is relatively rare in post-conflict development initiatives, since the external actors tend to reserve "most key decision-making authority" (p. 4). Perhaps the interaction between the beekeepers and the EU can best be described as an example of what Donais terms "sustainable peacebuilding" (p. 14). Sustainable peacebuilding requires "negotiated hybridity" between both insiders and outsiders "in which the division of responsibilities between outsider and insider is constantly calibrated and adjusted as a means to advancing the peace process" (p. 14, 21). Like the case of the beekeepers, the decision of Turkish Cypriot farmers to commence pomegranate production is likely another example of sustainable peacebuilding.

The case of pomegranate production in north Cyprus can be approached from several perspectives. This paper concentrates on intersection of two of those: (1) the adoption of pomegranates as a form of crop switching and (2) the adoption of pomegranates as a result of overcoming a collective action problem through sustainable peacebuilding. By promoting local ownership and sharing responsibility, an external actor helped the TCC surpass the capital and technical barriers that had previously prevented the implementation of a climate change solution.

\section{Climate Considerations in Cyprus}

Climate change has exacerbated Cyprus' water shortages (Shoukri and Zachariadis 2012; Zachariadis 2010; EEA 2009) Cyprus has experienced extended periods of drought since the 1970s; increased demand has made the issue of water availability particularly acute (BBC 2010). In an attempt to rectify this issue, north Cyprus agreed to the construction of an underwater freshwater pipeline connected to Turkey. Referred to as Barış Su ("Peace Water"), this pipeline was expected to be completed sometime in 2014; however, it was slightly behind schedule and just over halfway completed in October of that year (Gies 2013; Sands 2014). In addition to political concerns over heightening north Cyprus' reliance on Turkey, there are also worries that the pipeline will only increase demand (Gies 2013). Water shortages have been particularly challenging for the agricultural sector. Citrus fruits, Cyprus' third most lucrative agricultural export, place considerable stress upon Cyprus' limited water resources; they originated in the tropics and have the greatest water consumption of Cyprus' irrigated crops (Sofroniou and Bishop 2014; Dworak and Berglund 2012). With Cyprus' continuing water limitations, relying on water-intensive crops like citrus fruits to drive the economy is not a sustainable development strategy.

The TCC's adoption of pomegranate farming was a response to climate change. Cyprus' competitive edge in the citrus market had been undermined by countries that do not share its climate constraints; farmers needed to implement crop switching to alleviate the growing expense and inefficiency of citrus production. By supporting the commercial pomegranate venture with financial and technical resources, an external actor helped the Turkish Cypriot realize crop switching and 
overcome the monetary and informational barriers to climate adaptation identified by Seo and Mendelsohn (2008) and Huda et al. (2005).

We argue that the Turkish Cypriot farmers, like the Turkish Cypriot beekeepers studied by Gokcekus et al. (2014), were constrained by the classic collective action problem. The individual farmers did not have the resource capacity to transition to an alternative crop. They lacked the necessary training and technical background to implement a successful crop-switching programme, and they also faced financial constraints. Furthermore, their resource challenges made collectivization unlikely as both technical and financial leadership were absent. Once the collective action problem was overcome, we attribute the success of the pomegranate programme to its incorporation of sustainable peacebuilding (Donais 2009). An external actor provided technical knowledge and the initial investment funds, but Turkish Cypriot farmers quickly accepted local ownership of pomegranate farming. With external assistance, the domestic actor was able to solve the collective action problem.

\section{The EU and USAID}

Although the EU has committed to assisting north Cyprus' economic development in the hope of the eventual reunification of north and south Cyprus, it was not the primary external actor involved in the development of north Cyprus' new pomegranate industry. Managing Cyprus' political divisions has required delicate manoeuvring by the EU. Until 2013, the EU was actually "unable to set up a delegation in the Turkish-controlled half. Instead, it had to establish a headquarters-based task force in the south with a local programme support office in the northern part of Cyprus" (Nielsen 2012). With this in mind, the EU's relatively behind-the-scenes involvement in the pomegranate initiative is understandable. Through its Economic Development and Growth for Enterprises (EDGE) programme, USAID was actually the main actor facilitating the adoption of pomegranate farming. The EU's involvement was mostly restricted to providing funding through grants.

Under EDGE, the multinational consultancy firm BearingPoint was awarded a six million dollar contract to assist the TCC with economic development. In the completion of this contract, BearingPoint released certain online reports-including a 127 page final report-detailing the development of alternative crop programmes in north Cyprus. According to the EDGE reports, "the US Government's primary policy objective in Cyprus" was fostering a "durable settlement" between the divided Greek and Turkish Cypriot communities (EDGE 2008b, p. 5). To facilitate this settlement, EDGE was commissioned "to improve banking practices, to strengthen business associations and services, and to provide firm-level assistance to promote enterprise competitiveness" (EDGE 2008a, p. 4). The programme was redefined to focus on sector-level initiatives after firm-level efforts failed to have a substantive impact on improving north Cyprus' competitiveness (EDGE 2008a, p. 6). Within the agricultural sector, EDGE focused on five 
alternative crop programmes: pomegranates, capers, cactus fruit, salicornia, and passion fruit. The pomegranate programme, initiated in 2006, was the first of these to be implemented.

\section{Selecting Pomegranates}

The decision to support the switch from citrus to pomegranate production was not so much related to the amount of water consumed by pomegranate trees as it was driven by the type of water they use. In fact, pomegranates trees require approximately the same amount of water as citrus trees (Sheets et al. 2013; Sauls 1998; FAO 2013). What makes pomegranates a viable solution for Cyprus' climate limitations is their ability to "endure greater water salination than citrus trees" (EDGE 2008a, p. 16). Pomegranates trees are hardier than citrus and can better process salt-contaminated water. As an island in a frequent state of drought, Cyprus' freshwater resources are limited. Additionally, Cyprus has contaminated much of its available groundwater through over-extraction. As groundwater has been over pumped, freshwater aquifers have become salinated (Anastasi 2012, p. 14). EDGE reports specifically acknowledged the "salination of the ground water," as a contributing factor in Cyprus' declining citrus market competitiveness (EDGE 2008b, p. 87). Güzelyurt (its Greek name is Morphou), a region in north Cyprus, had been particularly affected by the increased salinity levels of the groundwater as it had significant citrus orchards. EDGE officials subsequently concentrated their initial pomegranate ventures in this region.

To further heighten the resource gains of the crop switch, the pomegranate varieties chosen by EDGE's commissioned experts were ones that flourished in drier climates and required fewer water resources. EDGE invited Agro Consultant and Agricultural Engineer Shlomy Raziel to provide expertise on the pomegranate programme. After analysing Cyprus' climate constraints, Raziel suggested that the phenology of the Wonderful variety might be best suited to the project as it had proved successful in similarly dry climates, such as Israel (EDGE 2008b, p. 66). Two other pomegranate varieties - the Herskovitz and the Acco that were both developed for Israel's climate-were also selected to be planted along with the Wonderful variety.

EDGE reports cited pomegranates" "consistent[cy] with the TCC's climate, topography and marketing [emphasis added] potential" as the reason they were selected to be the alternative crop initiative's prototype (EDGE 2008a, p. 33). As discussed, pomegranates had climate and environmental advantages over citrus fruits. However, the programme's ultimate success was also attributable to the market advantages of switching. Heightened competition from countries without the production difficulties of Cyprus' environmental constraints meant citrus producers were experiencing declining rates of return on their investments (EDGE 2008 b, p. 87). Simultaneously, demand for pomegranates increased due to the fruit's designation as a nutritional "superfruit" (Cassell 2012). Despite being a 
relatively new venture, market demand for the pomegranates produced through the EDGE programme has been such that participants have repeatedly sold the entirety of their yearly crop. All first quality fruits (those with traits most attractive to consumers) are consumed by the international market. The environmental gains of switching to pomegranate production were significant; the market benefits were equally important.

\section{Programme Design and Implementation}

Pomegranates are not a new fruit to Cyprus. During the nineteenth and early twentieth century, they were actually one of Cyprus' primary articles of export (Kahramanoglu et al. 2014; Usanmaz 2013, p. 2). The conflict that separated the island ended this trade and pomegranate orchards declined. Before the implementation of EDGE's alternative crops programme, pomegranates were either grown mostly for personal usage or "only remained around other fruit orchards as wind barriers" (Usanmaz et al. 2014, p. 62).

Prior to publicly advertising its alternative crop programmes, EDGE consultants exerted considerable effort in pre-emptively alleviating public backlash against perceived "replacement" crops (EDGE 2008b, p. 86). To protect the pomegranate programme from critics who claimed that it would subvert the livelihood of citrus growers, EDGE required that the land used by the growers be "unused, arid land" (p. 86). This stipulation meant that EDGE personnel had to devote additional resources to identifying land that fit this criteria and assisting the farmers with funding and developing drip irrigation systems to make the land productive. However, it did succeed at reducing local suspicions and had a positive long-term impact in the sense that in increased the amount of productive land available to Turkish Cypriot farmers. EDGE began publicly advertising its alternative crop programmes through various local channels in 2006. Of the five proposed projects, pomegranates received the greatest community interest. Twenty-two Turkish Cypriot farmers responded to the initial outreach efforts with 17 agreeing to EDGE's programme requirements. Farmers participating in the programme had to agree to the following:

(a) sign a Memorandum of Understanding (MoU) that outlined their responsibilities, (b) put some of their own monetary resources into the project, which usually came in the form of purchasing the plants, and (c) allow EDGE experts access to the alternative crops fields/ orchards to inspect the crops and offer advice on how to achieve the best harvest. (EDGE 2008b, p. 86)

The programme's Phase One focused on planting the pomegranates. EDGE arranged for Shlomy Raziel to visit the pomegranate orchards every 6-8 weeks in order to provide the farmers with on-site technical expertise (EDGE 2008b, p. 86). Prior to the actual planting of the pomegranate trees, EDGE required the farmers to attend training sessions on financial management, orchard establishment, and tree 
Table 1 Timeline of pomegranate production

\begin{tabular}{l|l}
\hline Year & Step \\
\hline 2006 & EDGE develops agribusiness programmes \\
\hline 2006 & Presented the programme to interested growers \\
\hline 2006 & Signed MOUs with the 17 participants in phase 1 \\
\hline $2006-2008$ & Training for growers \\
\hline $2006-2007$ & Establishment of the orchards \\
\hline 2007 & Planted pomegranate trees \\
\hline 2008 & Installed irrigation systems in orchards \\
\hline 2010 & First harvest \\
\hline 2011 & Establishment of Alnar Ltd \\
\hline 2011 & Alnar awarded EU rural development grant \\
\hline & Establishment of the Alnar processing facility \\
\hline
\end{tabular}

planting. After the 17 participating farmers planted the 18,750 trees on 51 acres of formerly arid land, EDGE supplemented Mr. Raziel's assistance with additional sessions on fertilizer application, pest management, winter pruning, and flower thinning (EDGE 2008b, pp. 117-118). Phase Two of the programme expanded the number of participating farmers to 22 , the planted acreage to 62 acres, and the number of trees to 22,450 (EDGE 2008b, p. 87).

Phase Three and Four of the programme were designed to develop the business side of this agribusiness programme. Under Phase Three, EDGE worked with the farmers to establish a fruit processing facility, while Phase Four focused on ensuring the sustainability of the growers' business model. Within Phase Three, 19 of the farmers incorporated the limited liability company Alnar Narcilık Ltd, and then using an EU grant of $150,000 €$, they built a pomegranate processing and storage centre. Through Alnar, the farmers have been able to export their products to five EU countries: Sweden, England, Belgium, Germany, and the Netherlands. The collective has plans to extend their international reach beyond these countries and to expand their internationally available product line to include pomegranate juice. Table 1 provides a summary timeline of the pomegranate programme's various components.

\section{Sustainable Peacebuilding}

The pomegranate programme has proven to be an archetype upon which to base future sustainable agribusiness development programmes. As the farmers have become more adept at growing pomegranates, the amount of fruit produced per tree has doubled from that of the initial yield (FreshFruit 2014). Exports have grown to almost five times Alnar's preliminary offering of $49 \mathrm{t}$; in 2013 Alnar exported $232 \mathrm{t}$ of fresh pomegranates (Alan 2013). The collective now produces around 
$30,000 \mathrm{~L}$ of pomegranate juice; since the producers do not use preservatives in their purely natural pomegranate juice, this is currently only consumed by the local market (FreshPlaza 2012). However, the company is exploring alternative means of bottling their juice in order to access new markets.

EDGE's pomegranate programme flourished due to elements of sustainable peacebuilding, like "negotiated hybridity" and "local ownership", that were built into the project. From the beginning, EDGE required the local actors to accept ownership of the programme through financial and organizational commitments. The monetary resources committed to the programme by the farmers were not insubstantial. Although USAID did provide some funding, its financial resources were mainly put towards training sessions and providing the farmers with technical assistance. As mentioned, the EU gave the Alnar collective a 150,000 € grant for the building of the processing plant. However, the entire project cost 450,000 $€$; after EDGE personnel assisted the farmers with developing a preliminary business plan, the local farmers were responsible for developing their own marketing strategy and contributing the remaining $300,000 €$ to the programme.

The local farmers were encouraged by the EDGE consultants to collectivize in order to foster long-term accountability among the farmers, develop local leadership, and ensure the sustainability of the programme. According to Ibrahim Kahramanoglu, managing director of Alnar, the producers collectivized in order to have ownership over the programme's business decisions. EDGE personnel suggested that Alnar apply for GLOBALGAP. certification, an independently evaluated standard designation that is often required by EU buyers. EDGE assisted Alnar with the initial application; recertifications have been handled by Alnar's personnel. After obtaining their initial certification, Alnar negotiated with the Cyprus Pomegranate Producers Union (a body of 36 pomegranate producers that has significant overlap with the producers of the Alnar collective) to handle exportation of their crops and extend Alnar's certification to cover the pomegranate products of the Union. Through Alnar, the pomegranate producers were able to develop the local leadership necessary to sustain and surpass what they achieved under the guidance of an external actor.

\section{Policy Implications}

Cyprus is certainly not the only country facing climate-related development challenges nor is it the only developing country with a collective action problem. Thus, the strategies that worked to foster sustainable pomegranate farming should be largely applicable elsewhere and to other agricultural products. From the case of pomegranate farming, the importance of the following factors is apparent.

When implementing crop switching, the market reputations of suggested replacement products carry considerable weight in determining whether one product is adopted over another. Both EDGE and the local farmers cited pomegranate's rapidly expanding reputation as a superfruit as an important factor in its selection. 
Even with the programme's success, the director of Alnar complained that Europe lacked a "pomegranate culture" and that pomegranate products were still far from reaching optimal market recognition (FreshFruitPortal 2014). Although the Turkish Cypriot farmers did have an interest in pomegranates prior to external involvement, identifying products that are both environmentally and market friendly is potentially an area in which developing countries need assistance.

The case of north Cyprus also demonstrated that locals were more likely to view crop-switching programmes favourably if they were initially perceived as augmenting, rather than replacing, traditional crops. EDGE's approach of planting pomegranates only on unused, arid land was able to mitigate any complaints from citrus producers. However, this approach did require significant exertion on the part of the external actor to both identify the available land and then provide the technical resources to make this land arable.

Local awareness of the suggested alternative crop also impacted the programme's overall success. Of the five alternative crop programmes developed by EDGE_-pomegranates, cactus, fruit, salicornia, capers, and passion fruit-the pomegranate programme has been most successful. Its success is at least partially attributable to the farmers' familiarity with pomegranates; the passion fruit programme has not inspired nearly as much interest among local actors. In interviews, the director of Alnar stressed that the pomegranate programme only succeeded (and was able to become highly successful) because of the awareness and enthusiasm of the local farmers for pomegranates. In addition to selecting crops that are both market and environmentally friendly, external actors also need to consider local preferences when designing development projects.

Local ownership is critical to achieving successful, sustainable peacebuilding through development. As is evident from the experience of the pomegranate producers, one of the simplest ways in which to inspire ownership is to require significant monetary commitments from the local participants. Overcoming the collective action problem that often characterizes developing societies does require financial input by the external actor (in order to pay for the necessary technical specialists); however, this input should be matched (within reason and considering circumstances) by local contributions. Equally important as the technical training it provided was the assistance EDGE gave the farmers in creating a business strategy. Motivated by EDGE, the producers were able to capitalize on their training and expand into exporting. Thus, in the case of Cyprus, the most important factor was not how much money was given, but how that money was used.

\section{Concluding Comments}

Pomegranate farming in north Cyprus might appear to be a rather niche case. However, it highlights a real problem that both developing and developed countries will soon-if they have not already-confront, namely, climate change. As the evidence from Cyprus indicates, post-conflict developing countries need financial 
and technical intervention from an external actor in order to implement even the simplest of climate change adaptations, such as crop switching. Additionally, postconflict states are often hobbled by the classic collective action problem and need an outside impetus to inspire them to accept local ownership of a development programme. Sustainable development is therefore a function of external and local actor coordination; using its superior resources, the external actor helps initiate the programme, and since the local actor also makes a significant contribution, the local actor commits to ensuring the programme's success.

The sustainability of similar climate change programmes can be further enhanced by selecting crops that are at least somewhat familiar to the local community and are also desired by the external market. A crop's phenology might be ideally suited to a certain region, but the local farmers need to also support its production. Identifying suitable crops will require the combined effort of external and local actors. Ultimately, enacting successful climate change adaptations requires both parties to share leadership responsibilities (Fig. 1).

Fig. 1 A sign indicating that this is a GLOBALGAP certified pomegranate orchard, in Morphou area, Cyprus

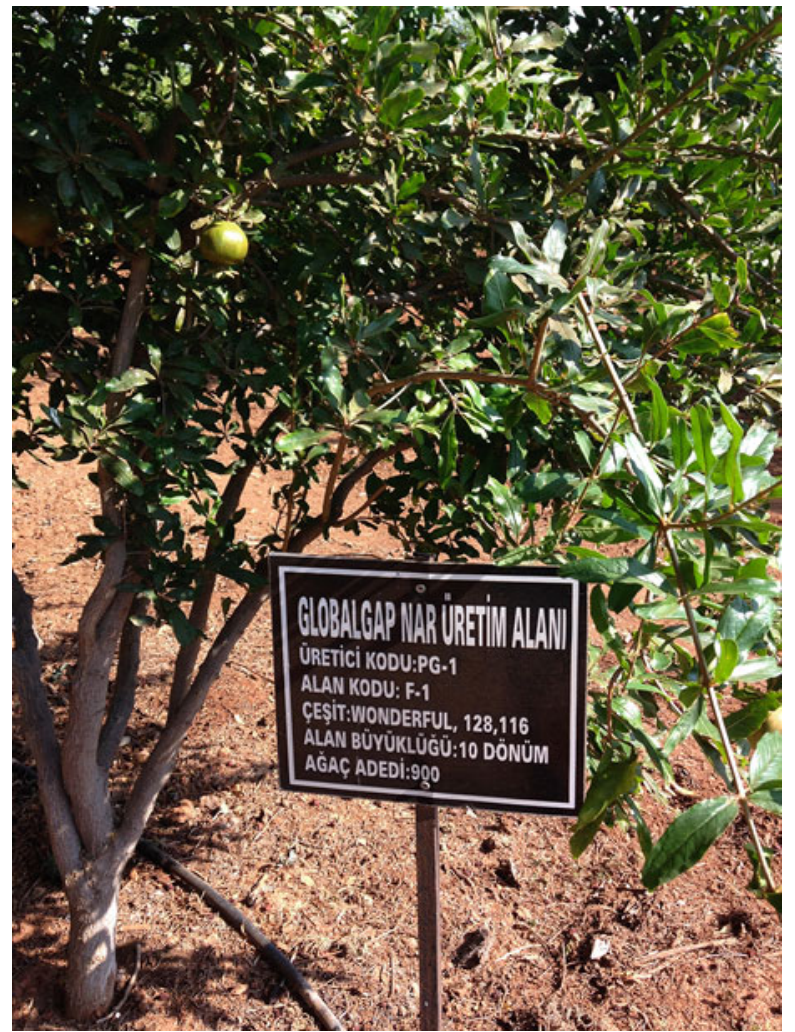


Open Access This chapter is distributed under the terms of the Creative Commons Attribution Noncommercial License, which permits any noncommercial use, distribution, and reproduction in any medium, provided the original author(s) and source are credited.

\section{References}

Alnar Narcilık Ltd (2013) Project—Alnar Narcılık Ltd Projesi, AB Bilgi Merkezi. http://vimeo. com/63579743

Alan D (2013) Dünyaya nar satıyoruz. Havadis, December 23, 2013. http://www.havadiskibris. com/Haberler/kibris/dunyaya-nar-satiyoruz/16757

Alnar Narcilik Ltd (2012) Mission. http://www.alnarpom.com/

Anastasi E (2012) The impact of climate change in water resources in Cyprus and possible human health effects. Cyprus University of Technology, Cyprus, pp 2-19. http://cyprus-institute.us/ Student-Records/2012/2012-Student\%20Records/Elena_Anastasi/elena\%20anastasi_climate\% 20change\%20paper.pdf

BBC (2010) Cyprus conflict closes leaders' eyes to water shortage. March 11, 2010. http://news. bbc.co.uk/2/hi/programmes/from_our_own_correspondent/8560424.stm

BBC (2011) Timeline: Cyprus. http://news.bbc.co.uk/2/hi/europe/country_profiles/1021835.stm

Cassell D (2012) Pomegranate retains superfruit status. Food Processing Magazine. http://www. foodprocessing.com/articles/2012/pomegranate-retains-superfruit-status/

Cyprus Profile (2013) Agriculture and Food: Quality not quantity. July 2013. http://www. cyprusprofile.com/en/sectors/agriculture-and-food

Donais T (2009) Empowerment or imposition? Dilemmas of local ownership in post-conflict peacebuilding processes. Peace Change 34:3-26

Dworak T, Berglund, M (2012) The role of water pricing and water allocation in agriculture in developing sustainable water use in Europe. European Commission Final Report Project Number 11589

EDGE (2008a) Unlocking the Turkish Cypriot Community's potential by providing keys to economic growth. http://pdf.usaid.gov/pdf_docs/pdacx162.pdf

EDGE (2008b) Final Report. Unlocking the Turkish Cypriot Community's potential by providing keys to economic growth, August 2008. http://pdf.usaid.gov/pdf_docs/pdacy313.pdf

EEA (2009) Water resources across Europe - confronting water scarcity and drought. EEA Report $2 / 2009$

FAO (2013) Crop water information: citrus. http://www.fao.org/nr/water/cropinfo_citrus.html

FreshFruitPortal (2014) Pomegranate culture lacking in Europe, says Cypriot grower. February 5,2014

FreshPlaza (2012) Turkey: ALNAR full range of pomegranate products. February 28, 2012. http:// www.freshplaza.com/article/93455/Turkey-ALNAR-full-range-of-pomegrate-prodcts

Gies E (2013) Northern Cyprus sees hope in water pipeline. The New York Times, April 3, 2013. http://www.nytimes.com/2013/04/04/world/europe/northern-cyprus-sees-hope-in-water-pipe line.html?pagewanted $=$ all\&_r $=0$

Gokcekus O (2008) The economics of the isolation of Turkish Cypriots. Turkish Cypriot Chamber of Commerce, Freebirds, Kyrenia

Gokcekus O, Bengyak K (2014) Peculiar dynamics of corruption: religion, gender, EU membership, and others. World Scientific, Singapore

Gokcekus O, Finnegan C, Cakal H (2014) External actors' role in solving local collective action problems in a post-conflict setting: a case study of the Turkish Cypriot beekeepers. Econ Peace Secur J 2:19-26 
Huda S, Sadras V, Wani S, Mei X (2005) Food security and climate change in the Asia-Pacific region: evaluating mismatch between crop development and water availability. Eur Foreign Aff Rev 10:535-552

Kahramanoglu I, Usanmaz S, Nizam I (2014) Incidence of heart rot at pomegranate fruits caused by Alternaria spp. in Cyprus. Afr J Agric Res 9:905-907

Kurukulasuriya P, Mendelsohn R (2008) Crop switching as a strategy for adapting to climate change. Afr J Agric Resour Econ 2:105-126

Lobell D, Burke M, Tebaldi C, Mastrandrea M, Falcon W, Naylor R (2008) Prioritizing climate change adaptation needs for foods security in 2030. Science 319:607-610

Nielsen N (2012) EU assistance to north Cyprus tangled in conflict. EUObserver, May 25, 2012

Olson M (1965) The logic of collective action. Harvard University Press, Cambridge, MA

Sands D (2014) Turkey builds massive pipeline to send drinking water to thirsty Cyprus. The Washington Times, September 30, 2014. http://media.washtimes.com/media/misc/2014/10/ 01/northerncyprus_revisedv3.pdf

Sauls J (1998) Home fruit production-pomegranate. Texas Citrus and Subtropical Fruits, December 1998. http://aggie-horticulture.tamu.edu/citrus/pomegranate.htm

Seo N, Mendelsohn R (2008) An analysis of crop choice: adapting to climate change in South America farms. Ecol Econ 67:109-116

Sheets M, Du Bois M, Williamson J (2013) The pomegranate. University of Florida. http://edis. ifas.ufl.edu/mg056

Shoukri E, Zachariadis T (2012) Climate change in Cyprus: impacts and adaptation policies. Environmental Policy Research Group Report 01-12

Sofroniou A, Bishop S (2014) Water scarcity in Cyprus: a review and call for integrated policy. Water 6:2898-2928

Usanmaz S (2013) Current situation and future of pomegranate production in Turkish Republic of Northern Cyprus. Master of Science Thesis, Lefke

Usanmaz S, Kahramanoglu İ, Yilmaz N (2014) Yield and pomological characteristics of three pomegranate (Punica granatum L) cultivars: wonderful, Acco and Herskovitz. Am J Agric For 2:61-65

Zachariadis T (2010) Residential water scarcity in Cyprus: impact of climate change and policy options. Water 2:788-814 